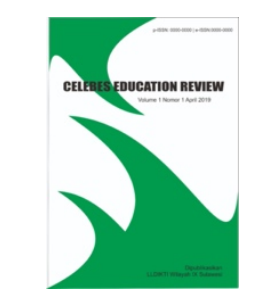

\author{
Celebes Education Review \\ http://journal.lldikti9.id/CER/index \\ Vol 2, No, 1, April 2020 \\ p-ISSN: 2656-7385 dan e-ISSN: 2684-7124
}

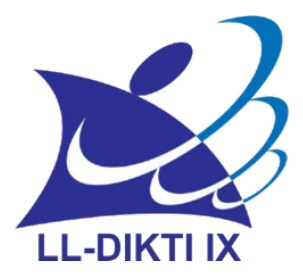

\title{
Penerapan Estimasi Skor Grup Domain untuk Meningkatkan Kualitas Pendidikan
}

\author{
Muhammad Tahir ${ }^{1}$, Baharullah ${ }^{2}$ \\ 1 Pendidikan Matematika, STKIP-YPUP Makassar \\ Email: tahirjakarta@gmail.com \\ 2 Pendidikan Matematika, Universitas Muhammadiyah Makassar
}

\begin{tabular}{l}
\hline \multicolumn{1}{c}{ Artikel info } \\
\\
Artikel history: \\
Received; 15-03-2020 \\
Revised:25-03-2020 \\
Accepted; 29-03-2020
\end{tabular}

Abstract. The purpose of this study is to demonstrate the application of domain group score estimates in an effort to improve the quality of education, with Item Response Theory (IRT), using the Maximum Likelihood Estimation (MLE) method with item characteristics of one parameter logistic model (L1P), and using the xcalibre 4.2 software program. Based on the estimated results of the domain group score can be used to evaluate the success of the implementation of certain education, for a number of groups of certain education units for example based on the group of districts / cities in a province. Previously, education evaluation was only limited to student learning achievement, but by using domain group score estimation, in addition to evaluating student learning outcomes, students could also evaluate groups of students. The results of the domain group score estimation research can facilitate policy makers to determine appropriate actions in order to improve the quality of education. In this study the number of respondents used was 1000 students who were grouped into 20 groups, and each group consisted of 50 students. It was found that if the minimum score that is considered successful is 80 , then there are still 7 groups of 20 groups of students who have not been successful because the scores are still below 80 , namely groups: $9,12,13,20,7,19$, and 14.

Abstrak. Tujuan penelitian ini adalah untuk menunjukkan penerapan estimasi skor grup domain dalam upaya meningkatkan kualitas pendidikan, dengan Item Response Theory (IRT), menggunakan metode Maksimum Likelihood Estimation (MLE) dengan karakteristik butir model logistik satu parameter (L1P), Serta menggunakan program software xcalibre 4.2. Berdasarkan hasil estimasi skor grup domain dapat digunakan untuk mengevaluasi keberhasilan pelaksanaan pendidikan tertentu, untuk sejumlah kelompok satuan pendidikan tertentu misalnya berdasarkan kelompok wilayah kabupaten/kota dalam suatu provinsi. Sebelumnya evaluasi pendidikan hanya terbatas pada prestasi belajar siswa saja, namun dengan menggunakan estimasi skor grup domain selain mengevaluasi hasil belajar siswa juga dapat mengevaluasi kelompok-kelompok siswa. Hasil penelitian estimasi skor grup domain dapat memudahkan pengambil kebijakan menentukan tindakan yang tepat dalam 
rangka peningkatan kualitas pendidikan. Pada penelitian ini jumlah responden yang digunakan adalah 1000 siswa yang dikelompokkan menjadi 20 kelompok, dan setiap kelompok terdiri dari 50 siswa. Ditemukan bahwa jika skor minimal yang dianggap sukses adalah 80, maka masih ada 7 kelompok dari 20 kelompok siswa yang belum sukses karena skornya masih di bawah 80, yaitu kelompok: 9, 12, 13, 20, 7, 19, dan 14 .

Keywords:

Skor domain, Skor

grup domain,

karakteristik butir,

IRT, MLE.
Coresponden author:

Email: tahirjakarta@gmail.com

artikel dengan akses terbuka dibawah lisensi CC BY -4.0

\section{PENDAHULUAN}

Evaluasi memegang peranan penting untuk mengungkap kompetensi penguasaan siswa dan kesulitan mereka dalam pendidikan. Dalam rangka mengidentifikasi keberhasilan suatu pendidikan diperlukan penilaian karena dengan hasil penilaian dapat digunakan mengukur prestasi siswa setelah mengikuti proses pendidikan. Fungsi utama penilaian adalah untuk mengukur prestasi siswa dan untuk memotivasi serta mengarahkan siswa belajar (Ebel \& Frisbie, 1991).

Hasil penilaian dibutuhkan dalam rangka meningkatkan kualitas pendidikan dengan cara meningkatkan prestasi belajar siswa di seluruh Indonesia. Semua bidang studi dapat dijadikan sebagai domain dalam penelitian ini, termasuk matematika. Berdasarkan laporan Trends in International Mathematics and Science Study (TIMMS) tahun 2015, Indonesia berada pada urutan ke 44 dari 49 negara dengan skor 397. Skor tertinggi diperoleh Singapura 618 dan skor terendah diperoleh Kuwait 353. Hal ini menunjukkan bahwa kemampuan matematika siswa Indonesia masih tergolong rendah (Wilkes, 2015). Terdapat sejumlah peneliti yang menaruh perhatian terhadap materi matematika antara lain (Saputro, 2015), (Tyas, Pangesti, \& Retnowati, 2017), dan (Sulistyowati, 2014).

Salah satu komponen penting untuk melakukan evaluasi pendidikan, yaitu tersedianya data skor prestasi belajar siswa dan prestasi belajar kelompok siswa, dengan estimasi skor grup domain dapat diperoleh skor prestasi belajar siswa dan prestasi belajar kelompok siswa. Estimasi skor grup domain dapat dilakukan dengan menggunakan Item Response Theori (IRT) (Linden \& Mcgraw-hill, 2010). Estimasi skor grup domain dapat menghasilkan estimasi skor setiap siswa dan hasil estimasi skor kelompok siswa. Kelompok siswa dapat berupa sekolah atau kelompok sekolah pada suatu wilayah. Dengan demikian estimasi skor grup domain dapat digunakan untuk melakukan peninjauan kembali oleh pengambil kebijakan pendidikan dalam rangka mengevaluasi keberhasilan pelaksanaan pendidikan agar dapat meningkatkan kualitas pendidikan pada suatu wilayah. Sebelumnya evaluasi pendidikan hanya terbatas pada prestasi belajar siswa saja, namun dengan menggunakan estimasi skor grup domain selain mengevaluasi hasil belajar siswa juga mengevaluasi kelompok-kelompok siswa.

IRT adalah suatu teori pemberian skor yang melepaskan ketergantungan antara butir tes dengan peserta tes. Ciri butir akan tetap sama, tidak menjadi soal peserta mana saja yang menempuhnya. Demikian pula ciri peserta akan tetap sama, tidak menjadi soal butir mana yang ditanggapinya (Susan E. Embretson \& Steven P. Reise, 2000). IRT baru dapat berlaku apabila memenuhi asumsi: unidimensi, independensi lokal, dan invariansi kelompok (Hambleton \& Slater, 1997), (Bichi, Hafiz, \& Bello, 2016), (Retnawati, 2014) dan (Dali S. Naga, 2013). Salah satu bagian penting dalam teori responsi butir adalah penentuan karakteristik butir yang dikenal sebagai model responsi butir, ada tiga model respon butir yaitu: Model logistik satu parameter (L1P) hanya menggunakan parameter taraf sukar butir b, model logistik dua parameter (L2P) 


$$
\frac{\partial^{2} \ln L}{\partial \theta^{2}}=-D^{2} \sum_{i=1}^{N}\left[P_{i}(\theta)\left(1-P_{i}(\theta)\right)\right]
$$

menggunakan parameter taraf sukar butir $\mathrm{b}$ dan daya beda $\mathrm{a}$, dan model logistik tiga parameter (L3P) menggunakan parameter taraf sukar butir b, daya beda a, dan faktor kebetulan betul c. Ciri peserta dinyatakan dengan parameter kemampuan $\theta$. Respon atau jawaban peserta terhadap butir dinyatakan dalam bentuk probabilitas jawaban benar $\mathrm{P}(\theta)$ (Linden \& Mcgraw-hill, 2010). Persamaan yang menghubungkan probabilitas jawaban benar dengan ciri butir serta ciri peserta ditulis sebagai berikut:

$$
P(\theta)=f(\theta, a, b, c)
$$

Pada penelitian ini, model responsi butir yang digunakan adalah model L1P (Baker, 2001). Baker menuliskan persamaannya sebagai berikut:

$$
P_{i}(\theta)=\frac{e^{D\left(\theta-b_{i}\right)}}{1+e^{D\left(\theta-b_{i}\right)}}=\frac{1}{1+e^{-D\left(\theta-b_{i}\right)}}
$$

Keterangan:

Konstanta D $=1,702$

Nilai $e=2,718$

$\theta=$ kemampuan responden

$b_{i}=$ taraf sukar butir ke-i.

Metode MLE adalah metode estimasi yang menggunakan iterasi untuk mendapatkan hasil skor estimasi. MLE didasarkan pada sejumlah data empiris dari sejumlah peserta yang mengerjakan sejumlah soal tes tertentu. Menurut Naga, secara probabilitas likelihood merupakan kombinasi jawaban benar dan jawaban salah. (Dali S. Naga, 1992). Misalkan secara umum jawaban satu peserta tes terhadap $\mathrm{N}$ butir adalah $X_{1}, X_{2}, X_{3}, \ldots X_{n}$. Pada butir ke- $i$ kita nyatakan jawaban benar sebagai $X_{i}=1$ dan jawaban salah sebagai $X_{i}=0$. Selanjutnya, untuk butir ke- $i$ tersebut kita menyatakan probabilitas jawaban yang benar sebagai $P_{i}(\theta)$ dan probabilitas dari jawaban yang salah sebagai $Q_{i}(\theta)$ dengan $Q_{i}(\theta)=1-P_{i}(\theta)$. Peluang probabilitas adalah:

$$
L(X \mid \theta)=P_{i}(\theta)^{x_{i}} \cdot\left(1-P_{i}(\theta)\right)^{1-x_{i}}
$$

Karena skor butir independen satu sama lain sesuai dengan persyaratan IRT, kita dapat menemukan fungsi kemungkinan (L) sebagai berikut:

$$
L=\prod_{i=1}^{N} P_{i}(\theta)^{x_{i}} \cdot\left(1-P_{i}(\theta)\right)^{1-x_{i}}
$$

$L$ maksimum pada saat $\frac{\partial L}{\partial \theta}=0$

Persamaan (3) berbentuk perkalian, agar lebih mudah dideferensialkan diubah menjadi bentuk penjumlahan dengan menerapkan logaritma sehingga diperoleh:

$$
\ln L=\ln \left[\prod_{i=1}^{N} P_{i}(\theta)^{x_{i}} \cdot\left(1-P_{i}(\theta)\right)^{1-x_{i}}\right]
$$

Estimasi $\theta$ dengan metode MLE diperoleh melalui pendekatan Newton-Raphson dengan rumus (6).

$$
\theta_{s+1}=\theta_{s}-\frac{\frac{\partial \ln L}{\partial \theta}}{\frac{\partial^{2} \ln L}{\partial \theta^{2}}}
$$

Berdasarkan persamaan (5) dan (6), ditemukan: 


$$
\begin{aligned}
& \theta_{S+1}=\theta_{s}+\frac{\sum_{i=1}^{N}\left[x_{i}-P_{i}(\theta)\right]}{D \sum_{i=1}^{N}\left[P_{i}(\theta)\left(1-P_{i}(\theta)\right)\right]} \\
& \theta_{s+1}=\theta_{S}+\frac{\sum_{i=1}^{N}\left[x_{i}-P_{i}(\theta)\right]}{D \sum_{i=1}^{N} P_{i}(\theta) Q_{i}(\theta)}
\end{aligned}
$$

Rumus iterasi Newton-Raphson (7) digunakan mengestimasi $\theta$ pada Model L1P. Jika selisih nilai $\theta_{2}-\theta_{1}$ masih besar maka nilai $\theta_{2}$ dimasukkan ke dalam rumus iterasi untuk menemukan $\theta_{3}$, dan seterusnya sampai ditemukan selisih antara dua $\theta$ berurutan menjadi sangat kecil, misalnya kurang dari 0,01. Nilai $\theta$ yang diperoleh pada saat iterasi dihentikan menjadi nilai estimasi $\theta$.

Skor grup domain adalah rata-rata skor domain dalam suatu kelompok responden (Pommerich, Nicewander, \& Hanson, 1999)., dihitung menggunakan rumus:

$$
\bar{\theta}=\frac{1}{n} \sum_{i=1}^{n} \hat{\theta}_{i}
$$

\footnotetext{
Keterangan:

$\bar{\theta}=$ Skor grup domain

$\hat{\theta}_{i}=$ skor domain responden ke-i

$i=1,2,3, \ldots, \mathrm{n}$ dengan $\mathrm{n}$ banyak responden perkelompok.
}

\section{METODE}

Metode yang digunakan dalam penelitian ini adalah metode eksperimental murni, dengan 1000 jumlah responden, dikelompokkan menjadi 20 kelompok dengan masing-masing kelompok terdiri dari 50 responden. karakteristik butir yang digunakan adalah model L1P. Teori penilaian yang digunakan adalah IRT, dan program software Xcalibre 4.2. (Guyer \& Thompson, 2014).

\section{HASIL DAN PEMBAHASAN}

Hasil estimasi skor domain yang diperoleh dengan menggunakan program software Xcalibre 4.2, kemudian selanjutnya menggunakan rumus (8) di semua grup, akhirnya diperoleh hasil estimasi skor grup domain skor tertinggi terjadi pada kelompok 16, dan terendah pada kelompok 14. Jika pengambil kebijakan menentukan bahwa kriteria skor minimum untuk skor grup domain yang dianggap berhasil adalah 80, maka setelah skor grup domain diurutkan dari skor terbesar ke skor terkecil, ditemukan bahwa masih ada 7 grup yang belum sukses, yaitu kelompok 9, 12, 13, $20,7,19$, dan 14 .

\section{SIMPULAN DAN SARAN}

Kebijakan evaluasi pendidikan sebaiknya didasarkan pada hasil penelitian tentang estimasi skor grup domain, untuk meningkatkan akurasi pengambilan keputusan terkait evaluasi pendidikan dalam rangka meningkatkan kualitas pendidikan.

Hasil penelitian estimasi skor grup domain dibutuhkan oleh kepala sekolah, guru, dan siswa. Selain itu hasil penelitian tersebut juga sangat dibutuhkan oleh pembuat kebijakan, dalam hal 
ini pemerintah, untuk itu diperlukan adanya penelitian estimasi skor grup domain secara berkala terhadap materi pelajaran tertentu yang dianggap penting dikuasai oleh siswa.

\section{UCAPAN TERIMAKASIH}

Penulis berterima kasih kepada Ketua Yayasan Pendidikan Ujung Pandang (YPUP) yang memberikan bantuan dana untuk penelitian ini, dan kepada semua yang terlibat sehingga artikel ini dipublikasikan. Terakhir kami do'akan buat semua yang terlibat dalam publikasi ini, semoga mendapat amal jariah. Aamiin.

\section{DAFTAR RUJUKAN}

Azwar, S. (2009). Efek Seleksi Aitem Berdasar Daya Diskriminasi Terhadap Reliabilitas Skor Tes. Buletin Psikologi, 17(1), 28-32. https://doi.org/10.22146/bpsi.11479

Baker, F. B. (2001). The Basics of Item Response Theory. ERIC Clearinghouse on Assessment and Evaluation. https://doi.org/10.1111/j.1365-2362.2010.02362.x

Bichi, A. A., Hafiz, H., \& Bello, S. A. (2016). Evaluation of Northwest University , Kano Post-UTME Test Items Using Item Response Theory, 5(4). Retrieved from https://files.eric.ed.gov/fulltext/EJ1132220.pdf

Bock, R. D., Thissen, D., \& Zimowski, M. F. (1997). IRT estimation of domain scores. Journal of Educational Measurement, 34(3), 197-211. https://doi.org/10.1111/j.1745-3984.1997.tb00515.x

Dali S. Naga. (1992). Teori Sekor Pada Pengukuran Pendidikan. Jakarta: Besbats.

Dali S. Naga. (2013). Teori Sekor Pada Pengukuran Mental. Jakarta: PT. Niagara Citrayasa, 2013, h. 78.

Ebel, R. L., \& Frisbie, D. A. (1991). Essentials of Educational Measurement (fifth edit). New Dethi: Prentice,Hall of India.

Falani, I., \& Kumala, S. A. (2017). Kestabilan Estimasi Parameter Kemampuan Pada Model Logistik Item Response Theory Ditinjau Dari Panjang Tes, 2(2). Retrieved from

https://scholar.google.co.id/scholar?hl=id\&as_sdt=0\%2C5\&q=KESTABILAN+ESTI

MASI+PARAMETER+KEMAMPUAN+PADA+MODEL+LOGISTIK+ITEM+RESPONSE+T HEORY+DITINJAU+DARI+PANJANG+TES+Ilham+Falani1\%2C+Siti+Ayu+Kumala2+J urnal+SAP+Vol.+2+No.+2+Desember+2017\&btnG=

Guyer, R., \& Thompson, N. A. (2014). Xcalibre Item Response Theory Calibration Software User Manual. Retrieved from www.assess.com

Hambleton, R. K., \& Slater, S. C. (1997). Item responsee theory models and testing practices: Current international status and future directions. European Journal of Psychological Assessment, 13(1), 21-28. https://doi.org/10.1027/10155759.13.1.21

Kern, H. (2004). the Estimation of Domain Scores Through Irt Methods. Retrieved from https://getd.libs.uga.edu/pdfs/kern_hayley_a_200705_ma.pdf 
Linden, W. J. Van Der, \& Mcgraw-hill, C. T. B. (2010). Item Response Theory, 81-88.

Mardapi, D. (2012). Pengukuran Penilaian \& Evaluasi Pendidikan. Yogyakarta: Nuha Medika.

Muhammad Tahir. (2020), Estimasi Skor Grup Domain Menggunakan Metode Maksimum Likelihood dan Modal Bayesian Ditinjau dari Panjang Tes, Makassar, Yayasan Barcode, ISBN 978-623-7942-70-2.

Pommerich, M., Nicewander, W. A., \& Hanson, B. A. (1999). Estimating average domain scores. Journal of Educational Measurement, 36(3), 199-216. https://doi.org/10.1111/j.1745-3984.1999.tb00554.x

Retnawati, H. (2014). Teori Respons Butir dan Penerapannya: untuk Peneliti, Praktisi Pengukuran dan Pengujian, Mahasiswa Pascasarjana, 135.

Ridlo, S. (2011). Perbandingan Model Graded Response dan Generalized Partial Credit pada Tes Pengetahuan Praktikum Biologi. Yogyakarta. Retrieved from http://eprints.uny.ac.id/42346/

Saputro, B. A. (2015). Media Pembelajaran Geometri Menggunakan Pendekatan Pendidikan Matematika Realistik Berbasis GeoGebra, 6(1), 33-38. https://doi.org/http://dx.doi.org/10.15294/kreano.v6i1.4471

Sulistyowati, Y. (2014). Pengembangan Perangkat Pembelajaran Bangun Ruang di SMP dengan Pendekatan Creative Problem Solving, 9, 219-232. Retrieved from http://journal.uny.ac.id/index.php/pythagoras

Susan E. Embretson \& Steven P. Reise. (2000). Item Response Theory for Psychologists. London: Lawrence Erlbaum associates publishers.

Tyas, F., Pangesti, P., \& Retnowati, E. (2017). Pengembangan Bahan Ajar Geometri SMP Berbasis Cognitive Load Theory Berorientasi pada Prestasi Belajar Siswa, 12(1), 33-46. Retrieved from http://journal.uny.ac.id/index.php/pythagoras

W. James Popham. (1974). Evaluation in Education. Los Angeles: Mrcutrhan Publishing Corporation, 1974, h.327.

Wilkes, S. (2015). Timms 2015. Retrieved from http://timss2015.org/wpcontent/uploads/filebase/mathematics/1.-student-achievement/1_0_4_mathstudent-achievement-infographic-grade-4.pdf 